\title{
ULTRAFLITRATION OF WASTEWATER WITH PRETREATMENT: EVALUATION OF FLUX DECLINE MODELS
}

\author{
H. K. Shon ${ }^{1}$, S. Vigneswaran ${ }^{1, *}$ J. Kandasamy ${ }^{1}$ and W.G. Shim ${ }^{2}$ \\ ${ }^{1}$ Faculty of Engineering, University of Technology, Sydney, P.O. Box 123, Broadway, \\ NSW 2007, Australia \\ ${ }^{2}$ Faculty of Applied Chemistry, Chonnam National University, Gwangju, Korea \\ * corresponding author (Tel.: 61295142629, Fax: 61295142633 Email: s.vigneswaran@uts.edu.au)
}

\begin{abstract}
Three different mathematical models relating the flux decline were investigated to quantify the effects of pretreatment in a membrane filtration system. The models used are empirical flux decline model, series resistance flux decline model and modified series resistance flux decline model. A cross flow ultrafiltration unit was used to study flux decline and organic removal from synthetic wastewater. Flocculation and adsorption pretreatments were carried out with ferric chloride $\left(\mathrm{FeCl}_{3}\right)$ and activated carbon of different doses. The three models could predict flux decline after different pretreatments and could be used as a pretreatment index to ultrafiltration.
\end{abstract}

Keywords: membrane filtration, pretreatment, flux decline, modeling, flocculation, adsorption, ultrafiltration

\section{INTRODUCTION}

The application of membrane processes in wastewater treatment has increased since the appearance of synthetic asymmetric membranes in 1960 [1]. A number of mathematical models have also been developed to describe membrane filtration. One approach has been to use transport modeling. The transport models that have been developed can be classified into different groups: i) porous (microfiltration-MF, ultrafiltration-UF) and nonporous (nanofiltration-NF, reverse osmosis-RO) membrane, ii) organic and inorganic and iii) different sizes of organic matter.

The transport models developed for nonporous membranes (NF and RO) consist of three types: i) homogeneous membrane models (solution-diffusion, extended solution-diffusion and solution-diffusion-imperfection models), ii) pore-based models (preferential sorptioncapillary flow, finely porous and surface force-pore flow models) and iii) irreversible thermodynamic models (Kedem-Katchalsky and Spiegler-Kedem models) [2]. The models of porous membranes (UF and MF) can be classified into: i) basic models based on HagenPoiseulle equation and Kozeny-Carman relationship), ii) Knudsen flow, iii) friction model and iv) concentration polarization (CP) model (resistance in series model, osmotic pressure model and mechanistic interpretation) [3]. 
These models can be also divided into four groups in terms of organic and inorganic characteristics of solutes [4]. The non-charged colloids principally follow the CP relationship, convection and diffusion, Nernst-Plank equation, resistance in series and cake filtration theory. The charged colloids follow a relationship of convection and diffusion, Donnan exclusion, extended Nernst-Plank equation, resistance in series and cake filtration theory. General organic matter follows the CP relationship, thermodynamic model, diffusivity, resistance in series and adsorption layers. Ions (anions) obey Donnan exclusion and extended Nernst-Plank equation. Few of these equations can be applied to ultrafiltration (UF) used in wastewater treatment because of organic fouling. The models can only be semi-empirical in wastewater conditions because it contains a mixture of different organic pollutants.

One of the simplest models in membrane filtration is one which relates the flux decline with time. As time proceeds, the permeate flux decreases with membrane fouling. A number of models have been developed to represent the flux decline. These models use system parameters (such as viscosity, pore size, membrane thickness and pressure) and flow balance equations with specific boundary conditions [5]. It is difficult to use these models in practical applications.

Previous work has not attempted to quantify the membrane filtration with pretreatment of biologically treated sewage effluent (BTSE) and this is probably due to the following reasons: i) the heterogeneous nature of organic matter in BTSE, ii) the removal of some of the organic matter during pretreatment which changes the characteristics of the feed to the membrane, iii) the addition of inorganic salt during the pretreatment of flocculation which affects the transport phenomenon, and iv) the decreasing initial concentration after different pretreatments which changes the initial conditions. It is therefore difficult to predict the membrane filtration when it is combined with a pretreatment. Therefore it is better to initially develop simple flux decline models. The models can be used to simulate practical applications where the model coefficients are calibrated with experimentally derived flux decline curves for specific wastewater and operational conditions.

In this paper, three different mathematical models that estimate the flux decline were investigated to determine how well they could simulate the effects of pretreatment. The models used are empirical flux decline (EFD) model, series resistance flux decline (SRFD) model and modified series resistance flux decline (MSRFD) model. The coefficients of each model were calculated to establish a correlation between the coefficients and the type of pretreatment for a given wastewater and membrane system. This would allow a comparison between different pretreatments and indicate their relative effectiveness.

\section{THEORETICAL}

\section{Empirical Flux Decline (EFD) Model}

The EFD model was developed by Cho [5]. The model is one of the simple flux decline 
models where EFD coefficients can be evaluated from experimental results using nonlinear regression. The equation consists of three flux-decline coefficients ( $\mathrm{k}_{0}, \mathrm{k}_{1}$ and $\left.\mathrm{d}\right)$ :

$\frac{\mathrm{J}_{\mathrm{t}}}{\mathrm{J}_{0}}=\frac{1}{1+\mathrm{k}_{0}\left(1-\mathrm{e}^{-\mathrm{k}_{1} \mathrm{t}}\right)+\mathrm{dt}}$

where $\mathrm{k}_{0}$ is the flux decline potential which is dimensionless, $\mathrm{k}_{1}$ is the rate constant, and $\mathrm{d}$ is the flux decline kinetic constant. The unit of $\mathrm{k}_{1}$ and $\mathrm{d}$ is $\min ^{-1}$.

\section{Series Resistance Flux Decline (SRFD) Model}

The SRFD model assumes that concentration, pore blocking and gel layer resistances are negligible compared with adsorption resistance. The fouling in synthetic wastewater is a result of weak adsorption, i.e., only the resistances due to membrane and adsorption were considered (Eq. 2). Membrane resistance is constant whereas adsorption resistance varies with time. Adsorption can be represented by Freundlich isotherm equation (Eq. 3).

$\mathrm{J}=\frac{\Delta \mathrm{P}}{\mu\left(\mathrm{R}_{\mathrm{m}}+\mathrm{R}_{\mathrm{a}}\right)}$

$\mathrm{R}_{\mathrm{a}}(\mathrm{t})=\mathrm{K}_{\mathrm{F}}{ }^{\prime} \times \mathrm{t}^{\frac{1}{\mathrm{n}^{\prime}}}$ (Freundlich form)

where $\mathrm{K}_{\mathrm{F}}$ ' and $1 / \mathrm{n}^{\prime}$ are SRFD constants with Freundlich equation and $\mathrm{t}$ is filtration time (min).

\section{$\underline{\text { Modified Series Resistance Flux Decline (MSRFD) Model }}$}

The MSRFD model considers the interfacial concentration $\left(\mathrm{C}_{\mathrm{m}}\right)$ at the membrane surface in the adsorption terms [5]. The MSRFD model only takes into account the adsorption resistance and the organic matter that accumulates on the membrane surface is considered as adsorbed material. The adsorption resistances $\left(\mathrm{R}_{\mathrm{a}}\right)$ can be measured using the interfacial concentration at the membrane surface by the concentration of the bulk and permeate. The interfacial membrane concentration $\left(\mathrm{C}_{\mathrm{m}}\right)$ is calculated using adsorption isotherm equations.

$$
\begin{aligned}
& \mathrm{J}=\frac{\Delta \mathrm{P}}{\mu\left(\mathrm{R}_{\mathrm{m}}+\mathrm{R}_{\mathrm{a}}\right)} \\
& \mathrm{R}_{\mathrm{a}}(\mathrm{t})=\mathrm{K}_{\mathrm{F}}{ }^{\prime \prime} \times \mathrm{C}_{\mathrm{m}}{ }^{1 / \mathrm{n} "} \text { (Freundlich form) } \\
& \mathrm{R}_{\mathrm{a}}(\mathrm{t})=\frac{\mathrm{a}^{\prime \prime} \mathrm{C}_{\mathrm{m}}}{1+\mathrm{b}^{\prime \prime} \mathrm{C}_{\mathrm{m}}} \text { (Langmuir form) } \\
& \mathrm{Ra}(\mathrm{t})=\frac{\mathrm{q}_{\mathrm{m}}{ }^{\prime \prime} \mathrm{C}_{\mathrm{m}} \frac{1}{\mathrm{n} "}}{1+\mathrm{K}_{\mathrm{s}}{ }^{\prime \prime} \mathrm{C}_{\mathrm{m}} \frac{1}{\mathrm{n} "}} \text { (Sips form) }
\end{aligned}
$$

The relationship between the permeate concentration $\left(C_{p}\right)$ and the bulk concentration $\left(C_{b}\right)$ is given by Eq. 8, which is based on a film theory.

$$
\mathrm{C}_{\mathrm{m}}=\mathrm{C}_{\mathrm{p}}+\left(\mathrm{C}_{\mathrm{b}}-\mathrm{C}_{\mathrm{p}}\right) \exp \left(\frac{\mathrm{J}}{\mathrm{k}}\right)
$$


$k=1.62\left(\frac{U^{2}}{d_{h} L}\right)^{0.33}$

where $\mathrm{K}_{\mathrm{F}}$ " and $1 / \mathrm{n}$ "' are MSRFD constants used with the Freundlich isotherm, a" and b" are MSRFD constants used with Langmuir isotherm, $\mathrm{q}_{\mathrm{m}}$ " is sorption capacity and $1 / \mathrm{n}$ "' and $\mathrm{K}_{\mathrm{s}}$ "'are constants used with Sips isotherm, $\mathrm{C}_{\mathrm{m}}$ is the interfacial membrane concentration $(\mathrm{mg} / \mathrm{L}), \mathrm{U}$ is the average velocity of the feed fluid $(\mathrm{m} / \mathrm{s}), \mathrm{D}$ is the diffusion coefficient of organic matter $\left(\mathrm{m}^{2} / \mathrm{s}\right), \mathrm{d}_{\mathrm{h}}$ is the equivalent hydraulic diameter $(\mathrm{m})$, and $\mathrm{L}$ is channel length (m). The diffusion coefficient was evaluated using a diffusion cell experiment.

The flux declines obtained for different pretreatments were fitted using EFD, SRFD and MSRFD models. The models were solved by nonlinear regression and Nelder-Mead methods.

\section{EXPERIMENTAL}

\section{Synthetic Wastewater}

This study was carried out with synthetic wastewater. This synthetic wastewater represents the biologically treated sewage effluent (BTSE) and its composition is given elsewhere [6].

\section{Flocculation and Adsorption Pretreatment}

Flocculation was carried out with ferric chloride $\left(\mathrm{FeCl}_{3}\right)$ of different doses. The samples were stirred rapidly for 1 minute at $100 \mathrm{rpm}$, followed by 20 minutes of slow mixing at 30 rpm, and 30 minutes of settling. Adsorption with powdered activated carbon (PAC) was then conducted using one liter of the pre-flocculated synthetic wastewater. Here, the PAC addition to pre-flocculated was to compare the different removal of organic matter. It is well known that flocculation removes large amount of organic matter, while PAC adsorption removes the majority of small organic matter [7]. The characteristics of PAC used are given in [7]. A predetermined quantity of PAC was stirred with mechanical stirrer at $100 \mathrm{rpm}$ for 1 hour. The synthetic wastewater was then passed through a $0.45 \mu \mathrm{m}$ microfilter to separate PAC particles prior to UF treatment.

\section{Membrane Set-up}

A cross flow UF unit (Nitto Denko, Corp.) was used to study the flux decline from synthetic wastewater (Figure 1). The synthetic wastewater was pumped to a flat sheet membrane module (effective membrane area $0.006 \mathrm{~m}^{2}$ ). The operating pressure and crossflow velocity were controlled at $300 \mathrm{kPa}$ and $0.5 \mathrm{~m} / \mathrm{s}$ by means of by-pass and regulating valves. The Reynold's number and shear stress at the wall were 735 and $5.33 \mathrm{~Pa}$, respectively. NTR 7410 (Nitto Denko Corp., Japan) membranes were used in this study (Table 1). 


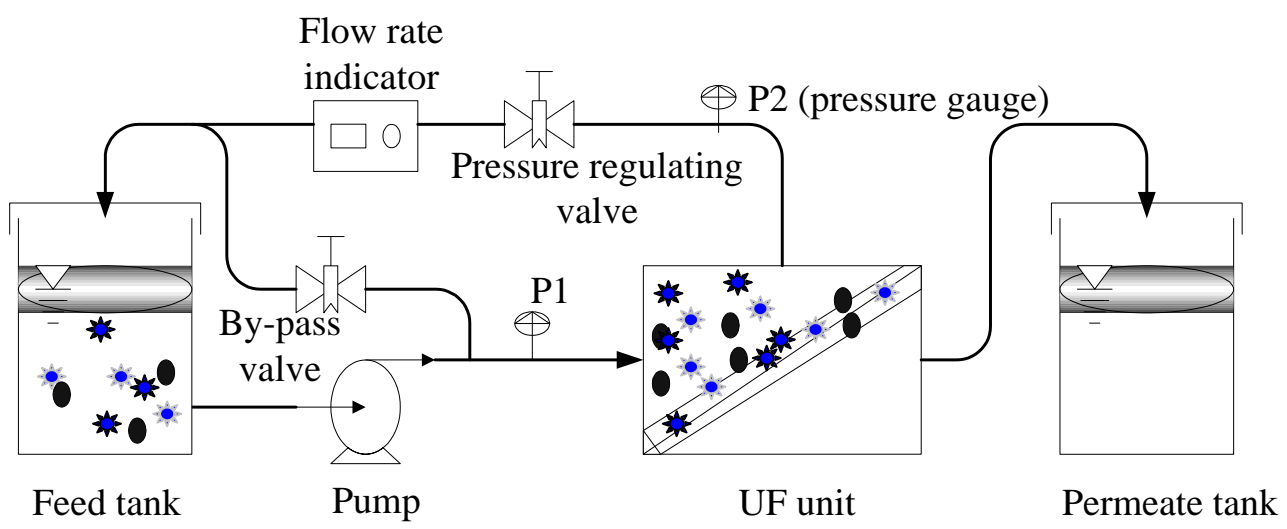

Figure 1 Schematic drawing of UF unit used in this study

Table 1 Characteristics of UF membrane used

\begin{tabular}{|c|c|c|c|c|c|c|}
\hline Code & Material & $\begin{array}{l}\text { MWCO* } \\
\text { (daltons) }\end{array}$ & $\begin{array}{r}\text { Contact } \\
\text { angle }\left({ }^{\circ}\right)\end{array}$ & $\begin{array}{l}\text { Zeta potential at } \\
\text { pH } 7(\mathrm{mV})\end{array}$ & $\begin{array}{l}\mathrm{PWP}^{* *} \text { at } 300 \\
\mathrm{kPa}(\mathrm{m} / \mathrm{d})\end{array}$ & $\begin{array}{c}\mathrm{R}_{\mathrm{m}} \text { (membrane resistance, } \\
\times 10^{12} \mathrm{~m}^{-1} \text { ) }\end{array}$ \\
\hline $\begin{array}{l}\text { NTR } \\
7410\end{array}$ & $\begin{array}{l}\text { Sulfonated } \\
\text { polysulfones }\end{array}$ & 17,500 & 69 & -98.63 & 1.84 & 14.1 \\
\hline
\end{tabular}

\section{RESULTS AND DISCUSSION}

EFD Model Prediction of UF Experimental Results with Different Pretreatments

Figure 2 presents the results of the experimental and simulated flux decline profiles of UF after a pretreatment of flocculation with different doses of $\mathrm{FeCl}_{3}$ and adsorption with different doses of PAC. The simulated curves fitted well with the experimental results. The flux-decline coefficients are presented in Table 2. The values of model coefficients are lower for the data of UF with pretreatment. The improvement to the flux decline was observed in UF following a pretreatment of $7-21 \mathrm{mg}-\mathrm{Fe} / \mathrm{L}$ flocculation. This resulted in a reduction of $\mathrm{k}_{0}$ and $\mathrm{d}$ values (Table 2). These values of these coefficients give an indication of the efficiency of different pretreatments. For example, the coefficients of $\mathrm{k}_{0}$ and $\mathrm{d}$ after a pretreatment of $14 \mathrm{mg}-\mathrm{Fe} / \mathrm{L}$ flocculation were similar to those after a pretreatment with 0.1 g/L PAC adsorption (Table 2). 

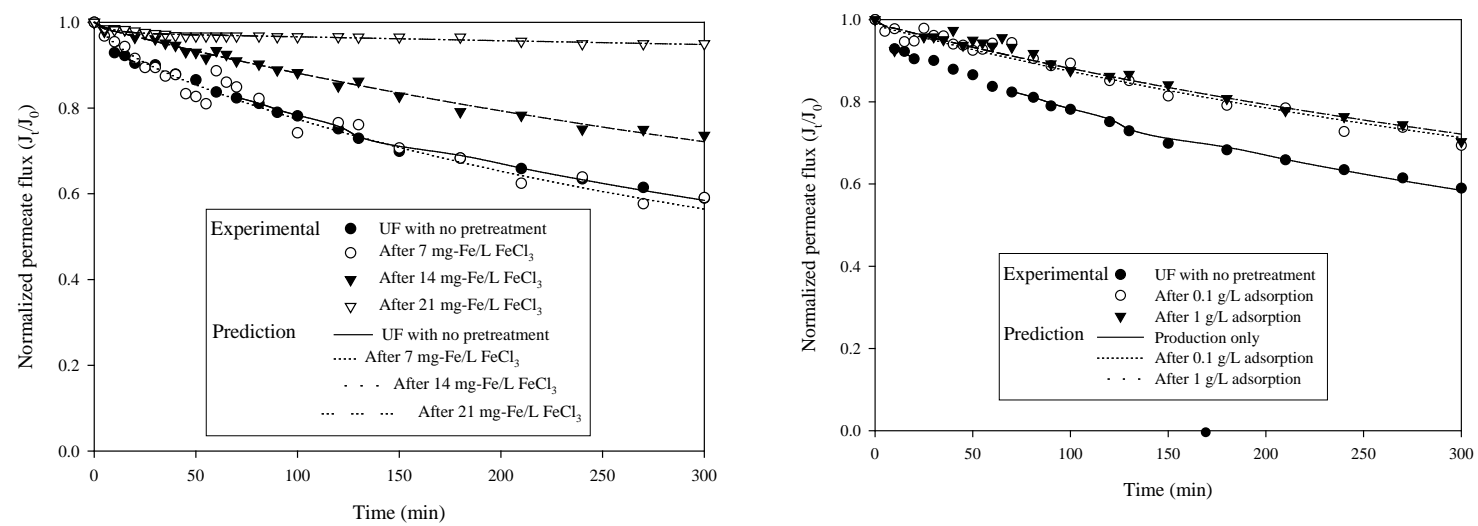

Figure 2 Experimental and predicted flux decline (EFD model) in UF after pretreatment (UF membrane used = NTR 7410; MWCO of 17,500 daltons; crossflow velocity = $0.5 \mathrm{~m} / \mathrm{s}$; transmembrane pressure $=300 \mathrm{kPa}$; Reynold's number: 735.5; shear stress: $5.33 \mathrm{~Pa}$ )

Table 2 Flux decline coefficients of EFD model with pretreatment $\left(\mathrm{k}_{1}=2.15 \mathrm{E}-02\right)$

\begin{tabular}{lcc}
\hline \multicolumn{1}{c}{ Pretreatment } & $\mathrm{k}_{0}$ & $\mathrm{~d}$ \\
\hline UF operation at $300 \mathrm{kPa}$ & $1.83 \mathrm{E}-01$ & $1.53 \mathrm{E}-03$ \\
After $7 \mathrm{mg}-\mathrm{Fe} / \mathrm{L}$ flocculation & $8.46 \mathrm{E}-02$ & $2.26 \mathrm{E}-03$ \\
After $14 \mathrm{mg}-\mathrm{Fe} / \mathrm{L}$ flocculation & $2.42 \mathrm{E}-02$ & $1.19 \mathrm{E}-03$ \\
After $21 \mathrm{mg}-\mathrm{Fe} / \mathrm{L}$ flocculation & $3.60 \mathrm{E}-02$ & $5.47 \mathrm{E}-05$ \\
After $0.1 \mathrm{~g} / \mathrm{L}$ adsorption & $1.24 \mathrm{E}-02$ & $1.31 \mathrm{E}-03$ \\
\hline
\end{tabular}

$\underline{\text { SRFD Model Prediction of Experimental Results }}$

The experimental results with different pretreatments were compared with the simulated curves using SRFD model. Table 3 presents the SRFD model coefficients obtained for UF experiments with different pretreatments. As membrane fouling decreased with flocculation pretreatment, the value of $\mathrm{K}_{\mathrm{F}}$ ' decreased (Table 3). The pretreatments of 14 mg-Fe/L flocculation (5.12E+10) and $0.1 \mathrm{~g} / \mathrm{L}$ PAC adsorption $(5.33 \mathrm{E}+10)$ were similar. The SRFD coefficient values may be used as a guide compare different pretreatment processes.

Table 3 Flux decline coefficients of SRFD model (Freundlich) with pretreatment $\left(1 / \mathrm{n}^{\prime}=\right.$ 7.75E-01)

\begin{tabular}{lc}
\hline \multicolumn{1}{c}{ Pretreatment } & $\mathrm{K}_{\mathrm{F}}{ }^{\prime}$ \\
\hline After $7 \mathrm{mg}-\mathrm{Fe} / \mathrm{L}$ flocculation & $1.03 \mathrm{E}+11$ \\
After $14 \mathrm{mg}-\mathrm{Fe} / \mathrm{L}$ flocculation & $5.12 \mathrm{E}+10$ \\
After $21 \mathrm{mg}-\mathrm{Fe} / \mathrm{L}$ flocculation & $1.01 \mathrm{E}+10$ \\
After $0.1 \mathrm{~g} / \mathrm{L}$ PAC adsorption & $5.33 \mathrm{E}+10$ \\
\hline
\end{tabular}

\section{$\underline{\text { MSRFD Model Coefficients Calculated for UF with Different Pretreatments }}$}

Figure 3 shows the results of the experimental flux profiles of UF after a pretreatment of 
flocculation with different doses of $\mathrm{FeCl}_{3}$ and adsorption with different doses of PAC. Also shown on Figure 3 are the predicted flux profiles by the MSRFD model. The simulated curves fitted well with the experimental results. Table 4 presents the variation of the bulk $\left(C_{b}\right)$, permeate $\left(C_{p}\right)$ and membrane $\left(C_{m}\right)$ concentrations with UF filtration and different pretreatments. The adsorption resistance is also given. With a pretreatment of flocculation using $21 \mathrm{mg}-\mathrm{Fe} / \mathrm{L} \mathrm{FeCl}_{3}$, the values of the $\mathrm{C}_{\mathrm{b}}, \mathrm{C}_{\mathrm{m}}$ and $\mathrm{R}_{\mathrm{a}}$ significantly decreased by 4.4 , 3.1 and 12.9 times, respectively. After $0.1 \mathrm{~g} / \mathrm{L}$ adsorption as a pretreatment, the values decreased by 2.2, 2.0 and 1.8 times, respectively.
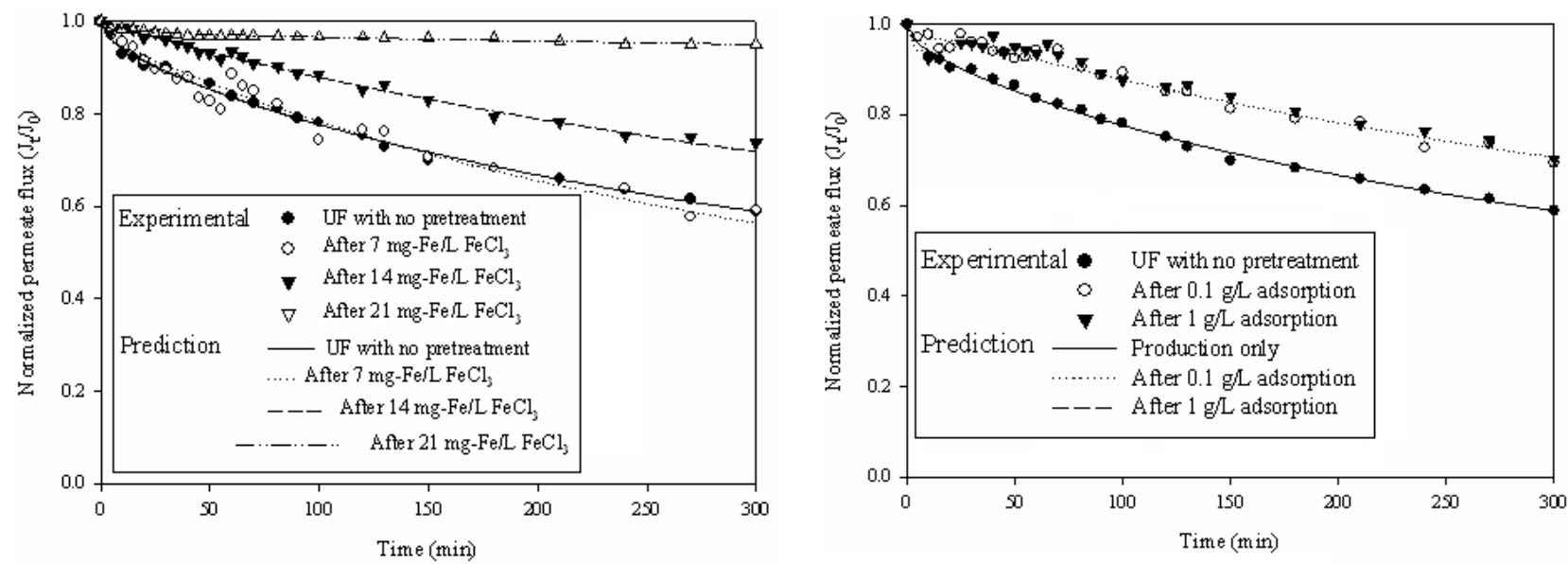

Figure 3 Experimental and predicted flux decline (MSRFD model) in UF after a) flocculation and b) PAC adsorption (UF membrane used = NTR 7410; MWCO of 17,500 daltons; crossflow velocity $=0.5 \mathrm{~m} / \mathrm{s}$; transmembrane pressure $=300 \mathrm{kPa}$; Reynold's number: 735.5; shear stress: $5.33 \mathrm{~Pa}$ )

Table 4 Concentration of organic matter and adsorption resistance

\begin{tabular}{lllll}
\hline & $\mathrm{C}_{\mathrm{b}}(\mathrm{mg} / \mathrm{L})$ & $\mathrm{C}_{\mathrm{p}}(\mathrm{mg} / \mathrm{L})$ & $\mathrm{C}_{\mathrm{m}}(\mathrm{mg} / \mathrm{L})$ & $\mathrm{R}_{\mathrm{a}}\left(\mathrm{m}^{-1}\right)$ \\
\hline $300 \mathrm{kPa}$ & 17.0 & 2 & 38.4 & $8.38 \mathrm{E}+12$ \\
$21 \mathrm{mg}-\mathrm{Fe} / \mathrm{L}$ flocculation & 3.86 & 1.1 & 12.5 & $6.48 \mathrm{E}+11$ \\
$0.1 \mathrm{~g} / \mathrm{L}$ adsorption & 7.59 & 1.5 & 19.6 & $4.62 \mathrm{E}+12$ \\
\hline
\end{tabular}

\section{CONCLUSIONS}

Three different mathematical models were investigated to quantify the effects of pretreatments on the flux decline. The three different models used were EFD, SRFD and MSRFD models. The coefficients of each model were derived from experimental results obtained under different conditions. These coefficients could be used to compare and correlate the efficiency of different types of pretreatments and could be used as a pretreatment index to ultrafiltration 


\section{ACKNOWLEDGMENT}

This work is supported by UTS Chancellor's postdoctoral research fellowship and ARC Discovery grants.

\section{REFERENCES}

[1] H.F. Ridgway, H.C. Flemming and J. Mallevialle Water treatment: membrane processes, American Water Works Association, Lyonnaise des Eaux and Water Research Commission of South Africa, New York, 1996.

[2] D. Bhattacharyya and M.E. Williams, Reverse osmosis In Chapter 22. Winston Ho, W.S. and Sirkar, K.K. Membrane handbook, New York, 1992.

[3] M. Mulder, Basic principles of membrane technology ( $2^{\text {nd }}$ edition). Kluwer Academic Publishers, Boston, 1996.

[4] S. Lee, Transport characteristics and sherwood correlation of natural organic matter in nanofiltration and ultrafiltration membranes. Doctoral thesis of philosophy, Gwangju Institute of Science and Technology, 2004.

[5] J. Cho, Natural organic matter (NOM) rejection by flux-decline of nanofiltration (NF) and ultrafiltration (UF) membranes. Ph.D. dissertation, Department of Civil, Environmental, and Architectural engineering, University of Colorado at Boulder, 1998.

[6] G.T. Seo, S. Ohgaki and Y. Suzuki, Wat. Sci. Technol. 35 (1997) 163-170.

[7] H.K. Shon, S. Vigneswaran, H.H. Ngo and R. Ben Aim, Water Res. 39 (2005), 147-153. 